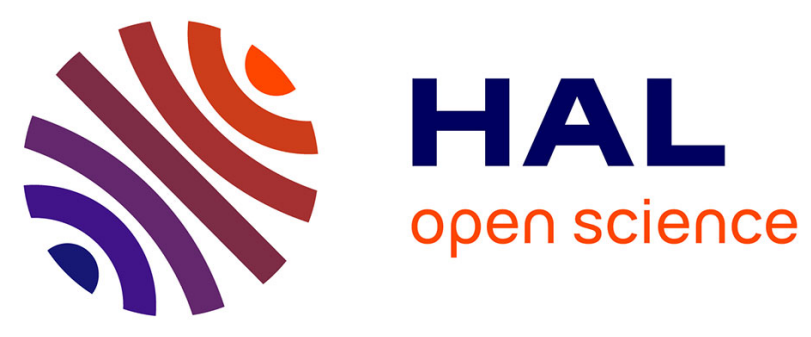

\title{
Switchable Two-Dimensional Waveguiding Abilities of Luminescent Hybrid Nanocomposites for Active Solar Concentrators
}

Soumaya Khlifi, John Bigeon, Maria Amela-Cortes, Noée Dumait, Goulc'Hen Loas, Stéphane Cordier, Yann Molard

\section{To cite this version:}

Soumaya Khlifi, John Bigeon, Maria Amela-Cortes, Noée Dumait, Goulc'Hen Loas, et al.. Switchable Two-Dimensional Waveguiding Abilities of Luminescent Hybrid Nanocomposites for Active Solar Concentrators. ACS Applied Materials \& Interfaces, 2020, 12 (12), pp.14400-14407. 10.1021/acsami.9b23055 . hal-02533161

\section{HAL Id: hal-02533161 \\ https://hal-univ-rennes1.archives-ouvertes.fr/hal-02533161}

Submitted on 14 Apr 2020

HAL is a multi-disciplinary open access archive for the deposit and dissemination of scientific research documents, whether they are published or not. The documents may come from teaching and research institutions in France or abroad, or from public or private research centers.
L'archive ouverte pluridisciplinaire HAL, est destinée au dépôt et à la diffusion de documents scientifiques de niveau recherche, publiés ou non, émanant des établissements d'enseignement et de recherche français ou étrangers, des laboratoires publics ou privés. 


\title{
Switchable 2D-waveguiding abilities of luminescent
}

\section{hybrid nanocomposites for active solar concentrators}

\author{
Soumaya Khlifi,,$^{\dagger}$ John Bigeon,,$^{\dagger}$ Maria Amela-Cortes, ${ }^{\dagger}$ Noée Dumait, ${ }^{\dagger}$ Goulc 'hen Loas, ${ }^{\dagger}$ \\ Stephane Cordier ${ }^{\dagger}$ and Yann Molard ${ }^{\dagger} *$ \\ †Univ Rennes, CNRS, ISCR - UMR 6226, ScanMAT - UMS 2001, FOTON - UMR6082 F-
}

\begin{abstract}
Passing from fossil energy sources to renewable ones, meanwhile answering the increasing world energy demand, will require innovative and low cost technologies. Smart photovoltaic windows could fulfill our needs in this matter. Their transparency can be controlled to manage solar energy, regulate interior temperature and illumination. Here we present the onepot synthesis of polymer dispersed liquid crystal (PDLC), in which highly red-NIR phosphorescent transition metal clusters are selectively embedded, either in the polymer, in the liquid crystal or in both phases. The PDLC matrix is used as a tuneable waveguide to transfer the emitted light from nanoclusters to the edge of the device where solar cells could be placed to convert it into electricity. Edge emission is obtained in both "off" and "on" state with a maximum intensity for the scattering “off” one. These doped PDLCs showing photoactivity features and high stability under voltage represent key stepping stones for integration in buildings, displays, and many other technologies.
\end{abstract}

KEYWORDS. smart window; metal cluster; luminescence; hybrid material; polymer dispersed liquid crystal 


\section{INTRODUCTION}

Solar energy is, among all renewable energy sources, the most suitable to meet the increasing demand of worldwide energy. Fiscal policies in western countries have led to a high public demand thus dropping down the prices of photovoltaic (PV) solar cells. However, new challenges arise to fulfill the increasing energy demand in particular in highly urbanized locations like megalopolis city centers that are growing vertically. Yet, building rooftops area, where solar panels are usually installed, have become too small to accommodate the necessary amount of PV modules required to insure the building energetic neutrality, as intended now by the EU. ${ }^{1}$ Therefore, integrating new innovative PV systems in newly constructs or old buildings meanwhile improving the quality of life of their residents is particularly relevant in our course to the energetic independency and to the 'zero-energy building' goal. An efficient strategy to reach this objective is to turn building facades into energy generation units by replacing the actual passive glazing windows with PV systems using efficient luminescent solar concentrators (LSC). ${ }^{2-5}$ This technology based on the integration of emissive dyes in a low cost and wave guiding material (glass or polymer) was first developed during the 1970 's. ${ }^{6,7}$ Sunlight is absorbed by dyes, reemitted at longer wavelength and further concentrated along the edge by internal reflection where PV cells are placed to collect and convert it to energy. Up to now, most of LSCs presented in the literature are static. ${ }^{2,4,8-12} \mathrm{We}$ propose here a new concept of LSC based on the direct and selective integration of emissive metal nanoclusters into smart windows. Indeed, these "smart windows" could offer several other advantages beside energy production as they gained considerable interest for both privacy and climate control as depicted in Figure 1. ${ }^{13}$ They can modulate their transparency to control the spectral and irradiance of incident sunlight, thus regulating interior temperature and adjusting interior room illumination. ${ }^{14-16}$ Recently, switchable windows coupled to a LSC additional layer were 
described, ${ }^{17,18}$ as well as self-powered switchable windows based on polymer dispersed liquid crystal (PDLC) technology. ${ }^{19}$ Taking into consideration that scattering solar concentrators have also been reported, ${ }^{20}$ we hypothesized that PDLC could be used to design an all-in-one device and serve as an active waveguiding medium for the light provided by incorporated emitters. As PDLC are biphasic organic materials containing a polymer phase and a liquid crystal phase, we aim also to study the influence of the emitter location (polymer, LC or both phases) on the waveguiding abilities and electro-optic properties of the resulting hybrid matrices. This point is particularly challenging as it cannot be achieved by a simple mixing of dyes within a host matrix but requires additional engineering steps in the design of dyes to target the desired phase. The ideal LSC should contain highly emissive dyes, stable under irradiation and showing a Stokes shift (energy gap existing between the absorption and emission maxima) as large as possible to avoid reabsorption losses, the dominant energy loss mechanism for this technology. According to Traverse et al., ${ }^{21}$ although they do not mention precisely which wavelength area they are dealing with, only Stokes shift higher than $100 \mathrm{~nm}$ would allow the production of LSC bigger than $1 \mathrm{~m}^{2}$. Octahedral transition metal cluster-based compounds meet all these needs. ${ }^{8}$ Most of them are prepared by solid state techniques as ternary salts of general formula $\mathrm{A}_{n} \mathrm{M}_{6} \mathrm{X}_{8}^{\mathrm{i}} \mathrm{X}_{6}^{\mathrm{a}}(\mathrm{A}=$ alkali cation, $\mathrm{M}=$ transition metal; $X^{\mathrm{i}}$ : inner ligand; $\mathrm{X}^{\mathrm{a}}$ : apical ligand), starting from earth abundant elements and, contain neither cadmium nor lead. ${ }^{22}$ These phosphorescent inorganic dyes can show an excellent photostability, ${ }^{23}$ quantum yield reaching unity, ${ }^{24}$ possess a very large Stokes shift, and, unlike quantum dots, such Stokes shift is achieved without the need of complex structure engineering. ${ }^{25}$ Several strategies have been employed to bypass their ceramic like behavior by integrating them in various "easy-to-handle" host matrices for large scale and public dedicated devices. ${ }^{26} \mathrm{~A}$ prerequisite is their homogeneous embedment in a host material. To do so, inorganic-organic phase 
segregation phenomena occurring when interactions between components are not strong enough to maintain a good dispersion must be discarded. Here we show that metal nanoclusters can be integrated in PDLC devices, and that the propagation of their emitted photons can be tuned by applying a low voltage on the device.
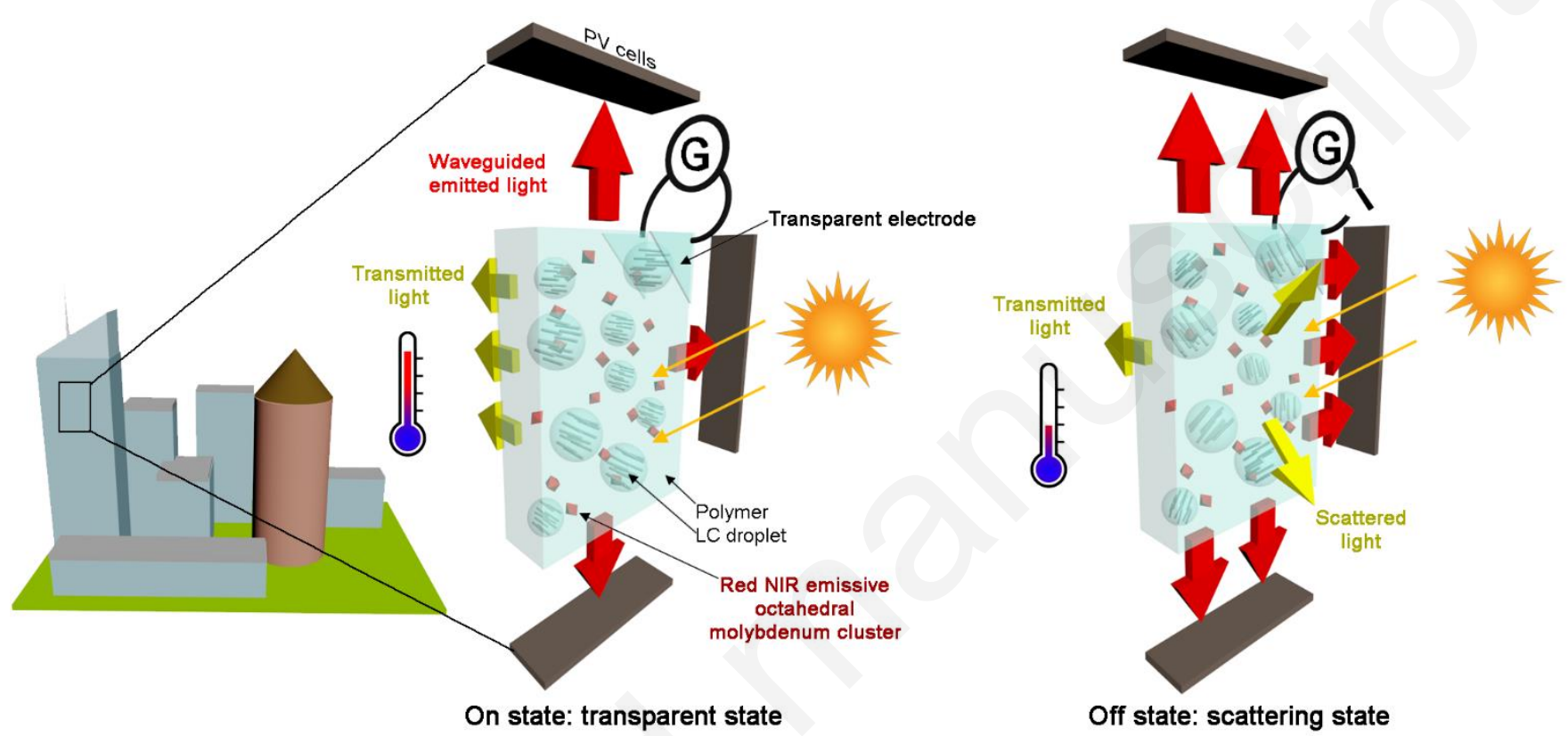

Figure 1. Concept of the active LSC window containing red NIR phosphorescent octahedral molybdenum nanoclusters. Schematic exploded representations of an active LSC window composed of a polymer dispersed liquid crystal matrix containing the phosphorescent inorganic emitter, surrounded by PV cells on its edges. The waveguided light and PV cells on the front left of the windows have been omitted for clarity. In the On state, nematic LC molecules contained in the droplets are aligned in the direction of the weak electric field, allowing a good transparency of the window; the material behave like a basic LSC; in the off state, incident sun light is scattered by the randomly aligned LC droplets which increases the waveguiding abilities of the LSC and limits the amount of transmitted light, thus reducing the building internal temperature. 


\section{RESULTS AND DISCUSSION}

PDLC materials are biphasic organic systems in which a LC material, most commonly a nematic LC, segregates into droplets within a polymer matrix. ${ }^{27}$ Figure 2 presents different ways to integrate a metal cluster ternary salt in a PDLC device. It can be introduced in the polymer phase only (case 1), in both phases (case 2), or in the LC phase only (case 3). Here, we use an ionic strategy to control the PDLC doping and homogeneity. ${ }^{28,29}$ This approach consists of replacing the native inorganic ternary salt alkali cations (usually, $\mathrm{Cs}^{+}$or $\mathrm{K}^{+}$ions) by functional organic ones. Hence organic cations were designed either to copolymerize with targeted organic monomers, 23,30 or to confer a nematogenic character to the hybrid assembly so that it becomes miscible with nematic organic liquid crystal mixtures (a mandatory step to avoid LC-LC phase segregation in the nematic LC droplets). ${ }^{31-33}$ All hybrids were synthesized as previously described with conform analytical data. ${ }^{23,32} \mathrm{LC}$ cells of $5 \mu \mathrm{m}$ thickness were filled up and the mixtures were copolymerized by UV-curing (see experimental section). In all cases, mixtures contained $60 \mathrm{wt} \%$ of polymer phase and $40 \mathrm{wt} \%$ of LC phase. The amounts of polymerizable nanocluster or clustomesogen (cluster containing liquid crystal, MoLC $)^{34,35}$ were set to $12 \mathrm{wt} \%$ within the polymer phase (Mo@PMMA) and 5wt\% in E7 (a commercially available nematic mixture made of cyanobiphenyl- and cyanoterphenyl-containing derivatives, see the experimental section for the exact composition). The LC-polymer phase segregation was then thermally induced ${ }^{36}$ by heating the cells above the LC to isotropic state transition temperature of liquid crystal mixtures and progressively cooled down to $25^{\circ} \mathrm{C}$. All cells were treated at the same time to confer them exactly the same thermal history. Figure 2 presents the optical micrographs observed under cross polarizers with a white light illumination and a UV irradiation (see ESI, Figures S1-S4 for full 
micrographs and inset Figure S2 for a SEM micrograph presenting the cross-section of the PDLC film contained in cell 1). LC droplets of $10-25 \mu \mathrm{m}$ in diameter could segregate from the mixture.

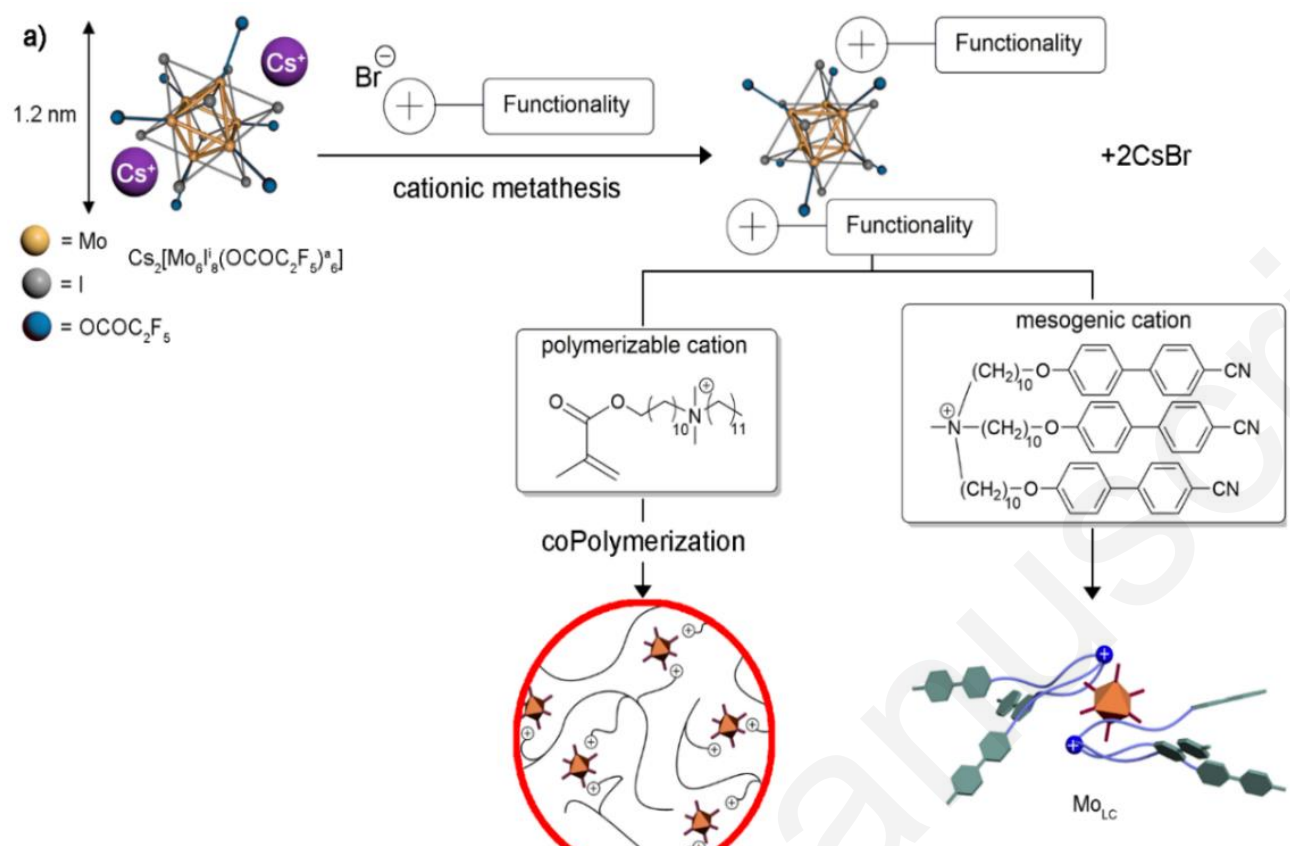

b)
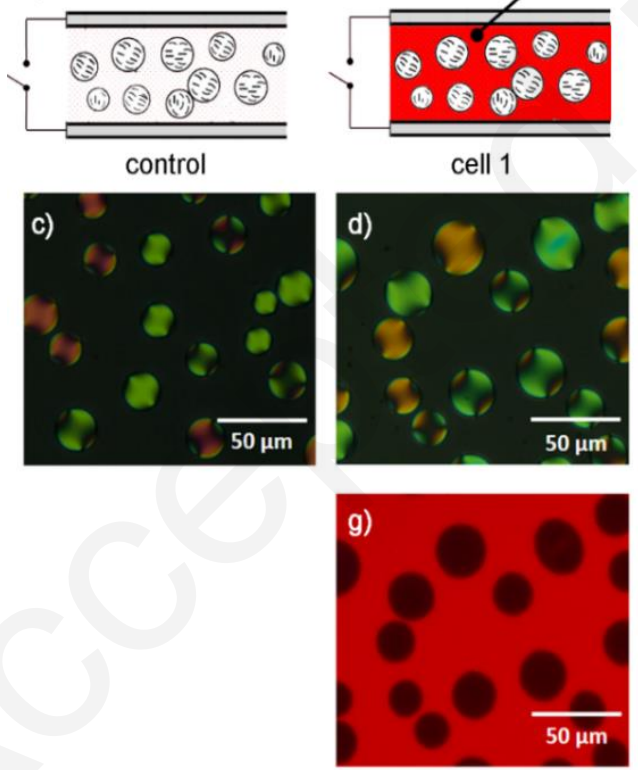

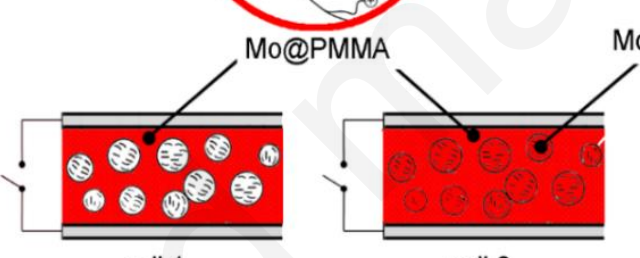

cell 2
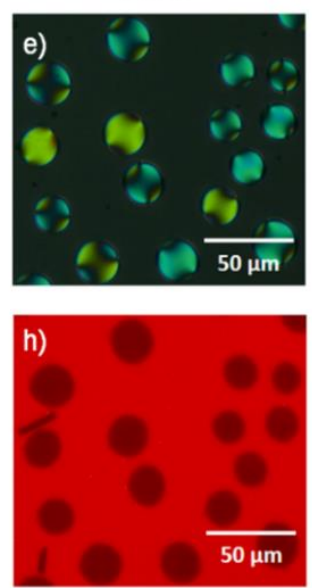

$\mathrm{Mo}_{\mathrm{LC}}$ at $5 \mathrm{wt} \%$ in E7
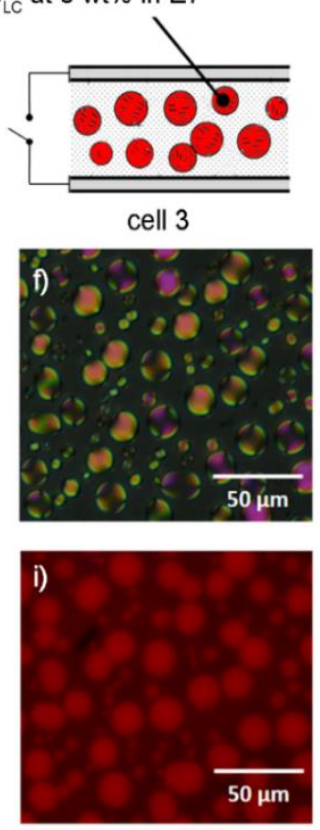

Figure 2. a) Schematic representation of the transition metal cluster salt used in this work and of the metathesis reaction leading to the exchange of its alkali cations with functional organic ones; b) schematic representation of the PDLC LC cells realized; c-f: polarized optical micrographs 
under white light of produced LC cells: c) control cell, d) cell 1, e) cell 2, f) cell 3; g-f: optical micrographs under UV irradiation of g) cell 1, h) cell 2 and i) cell 3.

Pictures taken under UV irradiation are very informative. They show for cell 1 that there is no emissive species in the LC phase which indicates an optimal phase segregation process from the polymer point of view; for cell 2: the difference observed in the red intensity between the polymer and LC droplets is mainly due to the difference in cluster concentration chosen a priori for both phases; for cell 3: a noticeable emission arises also from the polymer matrix showing that part of the doped LC mixture is miscible within the polymer. This partial solubility is well $\mathrm{known}^{37}$ and needs to be taken with care as it implies a variation in the LC mixture components concentration often leading to changes in the transition temperature. Nevertheless, LC droplets emit much more than the surrounding polymer which confirms the higher concentration of clusters in the LC phase. Note that although the same protocol was used in the LC-polymer phase segregation procedure, cell 3's droplets appear smaller and more polydispersed compared to the three other cases.

Emission properties were then investigated on the mixtures before and after integration into the cells. Cell 1 was also opened after being filled to observe the influence of air on the emission properties of hybrid matrices. For the sake of comparison, emission properties of neat $\mathrm{Cs}_{2} \mathrm{Mo}_{6} \mathrm{I}_{8}\left(\mathrm{OCOC}_{2} \mathrm{~F}_{5}\right)_{6}$ cluster are also reported. Steady state emission spectra and time resolved emission studies data are gathered in Table 1. Emission lifetime measurements are very instructive about the cluster environment: octahedral clusters are phosphorescent compounds whose triplet excited state reacts efficiently with surrounding triplet oxygen $\mathrm{O}_{2}\left({ }^{3} \Sigma_{\mathrm{g}}{ }^{-}\right)$to generate the reactive and emissive $\mathrm{O}_{2}\left({ }^{1} \Delta_{\mathrm{g}}\right) .{ }^{38}$ Hence, the $\mathrm{Cs}_{2} \mathrm{Mo}_{6} \mathrm{I}_{8}\left(\mathrm{OCOC}_{2} \mathrm{~F}_{5}\right)_{6}$ triplet state lifetime decreases from 269 $\mu$ s for a fully deaerated acetone solution to $2 \mu \mathrm{s}$ for an aerated one. ${ }^{39}$ The same trend is observed for Absolute Quantum Yield (AQY) values. 
Table 1. Threshold voltage $\left(\mathrm{V}_{\text {th }}\right)$ of devices, excited state lifetimes ( $\tau_{\mathrm{i}}$ and respective contribution in parenthesis, $\lambda_{\text {obs }}=690 \mathrm{~nm}$ ), and absolute quantum yield (AQY) values in air or $\mathrm{N}_{2}$ saturated atmosphere of clusters in the material precursor and once embedded in the device, with (ON) or without (OFF) voltage.

\begin{tabular}{|c|c|c|c|c|c|}
\hline & \multirow[t]{2}{*}{$\begin{array}{l}\mathrm{V}_{\text {th }} \\
{\left[\mathrm{V} \mu \mathrm{m}^{-1}\right]}\end{array}$} & \multicolumn{2}{|c|}{$\begin{array}{l}\tau_{\mathrm{i}}(\text { contribution })^{\mathrm{c}} \\
{[\mu \mathrm{s}]([\%])}\end{array}$} & \multicolumn{2}{|c|}{$\begin{array}{l}\mathrm{AQY}^{\mathrm{c}} \\
\left(\lambda_{\mathrm{exc}}=365 \mathrm{~nm}\right)\end{array}$} \\
\hline & & OFF & ON & air & $\mathrm{N}_{2}$ \\
\hline $\mathrm{Cs}_{2} \mathrm{Mo}_{6} \mathrm{I}_{8}\left(\mathrm{OCOC}_{2} \mathrm{~F}_{5}\right)_{6}{ }^{\mathrm{a}}$ & - & $269^{b}$ & - & 0.02 & 0.49 \\
\hline Mo@PMMA ${ }^{\mathrm{a}}$ & - & $135^{\mathrm{b}}$ & - & 0.02 & 0.27 \\
\hline \multirow[t]{2}{*}{ MolC } & - & $29(0.69)$ & - & 0.20 & 0.70 \\
\hline & & $13(0.31)$ & & & \\
\hline \multirow[t]{2}{*}{ MoLC /E7 } & - & $3.1(0.07)$ & - & 0.02 & 0.09 \\
\hline & & $0.84(0.93)$ & & & \\
\hline \multirow[t]{2}{*}{ Cell 1 (Open cell) } & - & $47(0.17)$ & - & 0.08 & 0.40 \\
\hline & & $18(0.83)$ & & & \\
\hline Cell 1 & 0.8 & 188 & 189 & - & - \\
\hline Cell 2 & 0.9 & 184 & 186 & - & - \\
\hline \multirow[t]{2}{*}{ Cell 3} & 1.2 & $185(0.47)$ & $108(0.28)$ & - & - \\
\hline & & $90(0.53)$ & $45(0.72)$ & & \\
\hline
\end{tabular}

Mesogenic clusters emission decay was fitted with two components that is in line with reported results. ${ }^{32}$ Part of the excited light is absorbed and reemitted by cyanobiphenyl units contained in the mesogenic cations which in turn transfer their energy to clusters. An important decrease of cluster lifetime components values and AQY is also observed when the mesogenic cluster is 
dispersed in E7. The lifetime decrease may be assessed to an increased $\mathrm{O}_{2}$ permeability of the MoLC/E7 mixture compared to MoLC itself. The AQY decrease comes from the fact that most of the incident light is absorbed by the cyanobiphenyl and cyanoterphenyl units contained in E7 with a poor transfer efficiency to MoLC. Surprisingly, once integrated in LC cells, the cluster emission lifetime largely increases to reach values in the same range as when clusters are in an oxygen free environment with emission lifetime values higher than $100 \mu$ s. This phenomenon is even more appreciable for cell 1 and 2 for which emission decays were fitted by a single exponential with a lifetime value of around $185 \mu \mathrm{s}$. When cell 1 was open, its emission decay was fitted with two shorter components. Interestingly, the AQY value of the open cell 1 is around 0.08 under air while it increases to 0.4 under $\mathrm{N}_{2}$ (value close to the one calculated for the cluster precursor in deaerated acetone solution). Note that this value is higher than the one calculated for Mo@PMMA under a $\mathrm{N}_{2}$ atmosphere. This is explained by an increased gas permeability of the PDLC matrix compared to the pure PMMA polymer matrix. Exploring the $1200-1400 \mathrm{~nm}$ window in air atmosphere for the open cell 1 upon UV excitation revealed the appearance of a signal centered around $1270 \mathrm{~nm}$ characteristic of $\mathrm{O}_{2}\left({ }^{1} \Delta_{\mathrm{g}}\right)$ emission (see ESI, Figure S5). The emissive $\mathrm{O}_{2}\left({ }^{1} \Delta_{\mathrm{g}}\right)$ singlet oxygen is generated by reaction of the cluster triplet excited state with the triplet oxygen $\mathrm{O}_{2}\left({ }^{3} \Sigma_{\mathrm{g}}^{-}\right)$contained in the atmosphere which is in good accordance with the shortening of its emission lifetime. ${ }^{38}$ Therefore, calculated lifetimes for the three devices indicate that clusters are in a nearly oxygen free environment that fully exploits their abilities to emit (see ESI, Figures S6-S12 for emission map and related integrated emission decays). Interestingly, the emission decay of cell 2 could also be fitted with a monoexponential decay. As cell 2 contains clusters in the polymer and LC phases, we could have expected at least the same behavior than for cell 3: an emission decay fitted with two components. The observed monoexponential character reflects the poor contribution of 
clusters embedded in the LC phase to the total luminescence signal. This is in line with the previous observations on raw material: in the LC droplets, the excitation light is mainly absorbed by the E7 host. The reversible changes in the emission lifetime values observed for cell 3 upon voltage application indicates a slight influence of the electric field on the cluster emission properties.

Within a PDLC droplet, LC molecules are usually oriented along the liquid crystal director whose alignment will depend on the voltage applied to the material. Without voltage (OFF state), these LC directors are randomly oriented from one droplet to another, causing a modulation of the refractive index within the material, leading to scattering and to the loss of transparency. In the field-on state, the droplet directors are uniformly aligned along the applied field. In this case, when the ordinary refractive index of LC matches the polymer host refractive index, the material appears transparent. ${ }^{40,41}$ Transmission measurements realized in the OFF and ON states on all cells show that the transmittance is slightly influenced by the cluster concentration. Transmission of undoped cell shows a cut off around $350 \mathrm{~nm}$ due to ITO layer and glass support, while an additional shoulder, due to cluster absorption bands, is observed between 350 and $500 \mathrm{~nm}$ in doped cells (see ESI Figures S13-S16). A maximum transmission value of $85 \%$ is achieved through the device in the ON state which is imparted to the inherent optical losses due to Fresnel reflection caused by the differences in refractive indexes at the air/glass/ITO/PDLC/ITO/glass/air interfaces. ${ }^{42}$ Therefore, in the ON state, our PDLC material is fully transparent in the cluster emission wavelength range. Although the devices are capable of continuous variation of opacity (see ESI video S1), it is important to evaluate how the clusters and polymers influence the E7 native switching properties. Hence transmittance vs applied voltage experiments were realized on all cells. Results are gathered in Figure 3a. Similar performances are observed for the control cell and cell 1 whose LC phases contain only E7, as expected. Cell 1 possesses the best $\mathrm{T}_{\mathrm{OFF}} / \mathrm{T}_{\mathrm{ON}}$ 
contrast ratio. Doping E7 with $5 \mathrm{wt} \%$ of clustomesogen does not have a strong impact on the Freedericksz transition threshold voltage $\left(\mathrm{V}_{\text {th }}\right.$, table 1), when the onset of switching of LC molecules is observed (i.e. when the transmittance begins to rise), as reported earlier. ${ }^{32}$ However, it has a significant effect on the transmittance vs applied voltage behavior. Indeed, the transition between the ON and OFF states is not as straightforward when the LC droplets are doped (cell 2 and cell 3) compared to when they only contain E7 (control cell and cell 1). The possible reason could be that the clustomesogens induce their symmetry up to a certain extent onto the nearest neighboring LC molecules constituting the unit volume. Their bulkiness imposes the application of a stronger electric field to align all molecules contained in the LC droplets. Interestingly, we observed a different behavior under voltage when both polymer and LC phases are doped (cell 2) compared to cell 3 where clusters were integrated only in the LC matrix. These differences may originate from an equilibrium between the cluster's "clustomesogen" and "polymerized" forms. Yet, it cannot be excluded that cationic exchanges occur in the material, and that part of cluster anions have their dianionic charge counterparted with one polymerized and one mesogenic cation, in particular at the LC-polymer interfaces. The higher $\mathrm{V}_{\text {th }}$ value observed for cell 3 is also assessed to the smaller size of LC droplets which implies a higher driving force to align LC molecules. ${ }^{40}$ Nevertheless, application of a sufficient voltage to turn the devices in the ON state, did not affect the metal cluster measured lifetime values (Figure 3d) which demonstrate the excellent dyes stability toward the application of an electric field. Figure 3b presents the set up used to observe the emission on the edge of the PDLC cell. The device is continuously excited perpendicularly with a laser at $448 \mathrm{~nm}$, while applying a $30 \mathrm{~V} \mathrm{AC} 1 \mathrm{KHz}$ square voltage in order to observe a full transmission switch and prevent ionic build-up, which can damage the LC cell. ${ }^{43}$ The emission is recorded using a spectrometer or a photodiode focused on the edge with a x 20 microscope 
objective. The response registered for cell 2 by the photodiode and the spectrometer with or without voltage are given in Figure 3c and Figure 3e, respectively. These measurements clearly show that the waveguiding abilities of the hybrid PDLC can be tuned. Moreover, as the emission signal is more intense in the OFF state than in the ON one, the waveguiding in the PDLC is more efficient in the OFF state than in the ON one. Hence, a reversible difference of $7 \%, 16 \%$ or $10 \%$ of the guided edge-emission intensity was measured in the OFF and ON states for cell 1, cell 2 and cell 3, respectively (see ESI, Figures S17-S19 for all spectra).

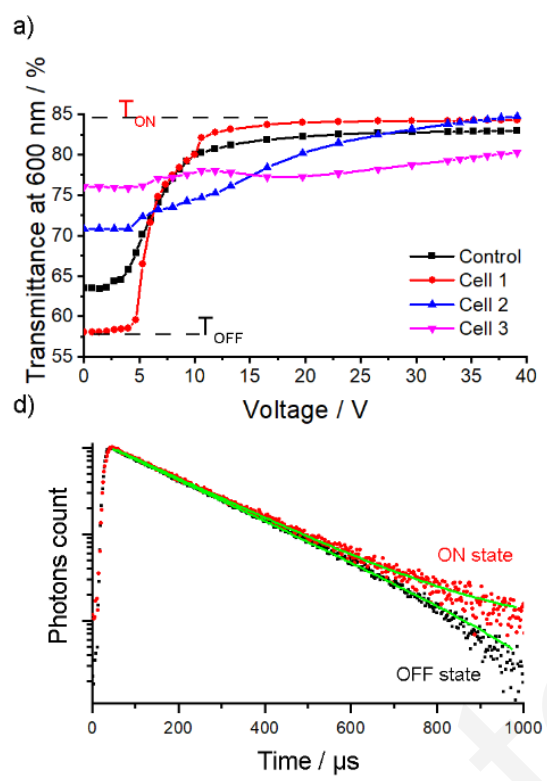

b)
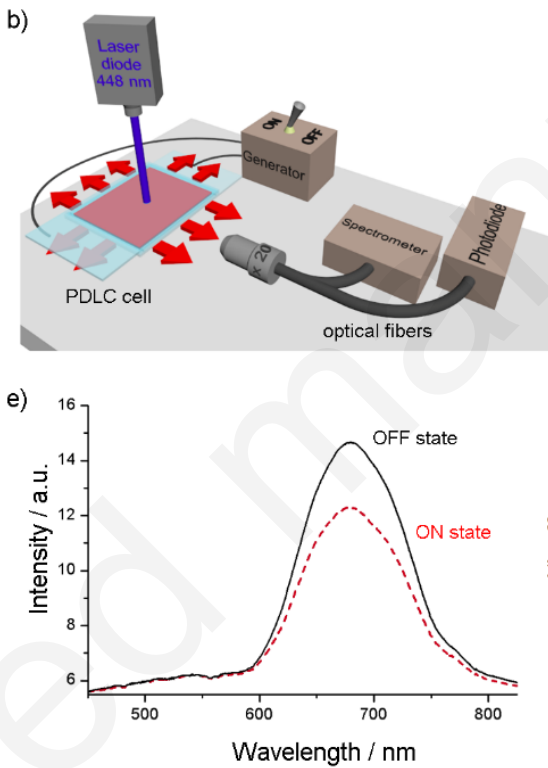
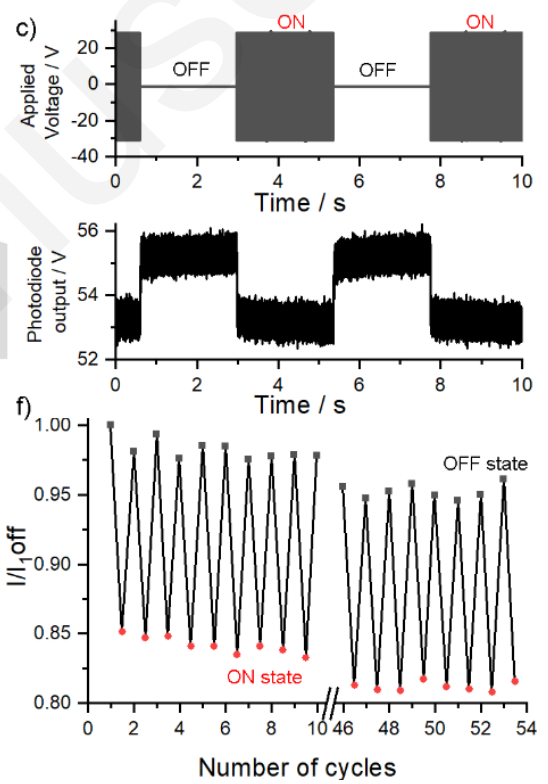

Figure 3. a) Transmittance $v s$ driving voltage; b) schematic representation of the experimental set - up used for the "emission-on-the-edge" measurements. Obtained data for cell 2: c) applied AC voltage and corresponding response of the photodiode vs time; d) integrated emission decay profile and related fitted curves (in green), off (black) and on (red) states; e) emission spectra in the off (plain black line) and on (dashed red line) states; and $\mathrm{f}$ ) fatigue studies of the edge emission in the off (black) and on (red) states. 
From these results, some trends can already be highlighted: in terms of power consumption, cell 1 prototype seems the most promising device, while cell 2 offers the best contrasts results in terms of edge emission. Cycling tests realized under laser excitation on about 50 ON-OFF cycles, revealed that these systems are very stable. In all cases, the emission intensity difference between the ON and OFF states is maintained after 50 cycles. Best results are obtained for cell 2 with a loss of only $2.5 \%$ of the emitted intensity at the end of the studies (Figure 3f and ESI Figures S20S22). The continuous laser excitation during the experiments leads to a local increase of the temperature. This affects the refractive index of the PDLC and explains such emission losses. However, in all cases, the emission intensity difference between the ON and OFF states is maintained. For cell 2, cycling tests were also conducted with the photodiode on 170 cycles (see ESI Figure S23) without noticing any damages, indicating the high electrical and environmental stability of the PDLC cells. At this stage, we wish to emphasize that the devices described herein remain proof-of-concept devices. Therefore, depending on environmental factors, parameters such as driving voltage, light transmission and waveguiding abilities can be optimized. Indeed, the nature of the polymer and LC phases, their ratio in PDLC, the droplets size that influences the ON/OFF contrast in transmittance and the driving voltage, ${ }^{44-48}$ and the cluster nature and concentration are belonging to the main parameters that affect the device efficiency. Our efforts in optimizing all these parameters will be reported in due course.

\section{CONCLUSIONS}

This work describes the first example of hybrid organic inorganic PDLC in which the inorganic nanofillers location is fully controlled. We have demonstrated how nanocluster compounds could be integrated in such biphasic material to design active luminescent solar concentrators for smart 
photovoltaic windows. By associating the inorganic polyanion with specifically designed organic cations, we showed that the emitters could be selectively introduced in the polymer, LC or both organic phases. The hybrid features high photo- and electrical- stability and fully reversible and tuneable waveguiding performances, which are key requirements for successful integration into diverse applications. In the on-state, our devices are transparent and behave like typical static LSC, while in the off-state, their transparency disappears and their waveguiding abilities increase notably. The best waveguiding contrast values are observed when the polymer and LC phases contain the emitter while the best electro-optical properties are obtained when only the polymer phase is doped. The described integration technique has the potential to be extended to other types of metal based clusters showing different emission-absorption properties. Our results indicate that octahedral metal clusters are not only ideal for low-cost, eco-friendly and smart solar cell concentrators, but also possess an excellent stability for switchable optoelectronics.

\section{EXPERIMENTAL SECTION}

Materials. E7 thermotropic nematic LC was purchased from Merck licristal®. This eutectic mixture contained 51 wt.\% 4-cyano-4'-n-pentyl-biphenyl, 25 wt.\% 4-cyano-4'-n-heptyl-biphenyl, 16 wt.\% 4-cyano-4'-n-oxyoctyl-biphenyl and 8 wt.\% 4-cyano-4' -n-pentyl-p-terphenyl. Methyl methacrylate (MMA) monomer was purchased from Aldrich and was distilled before use. 2hydroxy-2-methylpropiophenone (HMPP) was provided by Specific Polymers and used such as a polymerization UV-photoinitiator. Ebecryl ${ }^{\circledR} 350$ was purchased from Cytec and used like a UV curable resin. LC cells were purchased from Awat Spółka z o.o. (Poland), AWAT2 standard with $9 \mathrm{~mm} \times 9 \mathrm{~mm}$ active area. The polymerizable cluster $\left(\mathrm{CatP}^{+}\right)_{2}\left[\mathrm{Mo}_{6} \mathrm{I}_{8}\left(\mathrm{OCOC}_{2} \mathrm{~F}_{5}\right)_{6}\right]^{23}$ and the clustomesogen ${ }^{32}$ miscible with E7 were synthetized by reported procedures with conform analysis. 
Emission measurements. Lifetime measurements and TRPL mapping were realized using a picosecond laser diode (Jobin Yvon deltadiode, $375 \mathrm{~nm}$ ) and a Hamamatsu C10910-25 streak camera mounted with a slow single sweep unit. Signals were integrated on a $30 \mathrm{~nm}$ bandwidth. Fits were obtained using origin software and the goodness of fit judged by the reduced $\chi 2$ value and residual plot shape. Absolute quantum yields in the solid state and in solution were measured with a C9920-03G Hamamatsu system. $\mathrm{O}_{2}\left({ }^{1} \Delta_{\mathrm{g}}\right)$ measurements were realized with a Hamamatsu H12397-75 NIR-PMT unit mounted on a IHR3 spectrometer. Excitation of thin films was realized with a $375 \mathrm{~nm}$ laser diode (Jobin Yvon deltadiode). Luminescence spectra in the liquid crystal phases were recorded with an Ocean Optics QE65000 CCD spectrophotometer by irradiating the samples directly on the microscope hotstage with a Nikon-INTENSILIGHT C-HGFI (UV 1 or UV2 filters). Cycling tests were performed by vertical optical coupling using continuous-wave $448 \mathrm{~nm}$ excitation. The optical setup is based on a vertical microscope with an objective $\mathrm{x} 8$ $(\mathrm{NA}=0.25)$. The pump spot $($ diameter $=3 \mathrm{~mm})$ is focused in the centre of the cell $($ power $=2.8 \mathrm{~mW})$. Edge emission was collected with an objective x20 (NA=0.30) at one of the slab edges, optimized thanks to a visible camera and analysed by a spectrometer or a photodiode. Photoluminescence spectra was recorded 10 seconds after switch (ON or OFF) was applied. No reabsorption process or shift of the emission band was observed after more than 100 repeated ON/OFF cycles. Voltage was provided by a homemade generator providing a tuneable AC square waved voltage $(1 \mathrm{kHz})$. When the edge emission of the cell was collected on a photodiode, the emission was analyzed vs time temporal on an oscilloscope. The cycling consists of alternation of 30 seconds ON-OFF cycle (1h40 experiment, 100 cycles). The $\mathrm{ON}$ state consists of $1 \mathrm{kHz}$ square voltage signal with peak 
amplitude of $30 \mathrm{Vpk}$ and average voltage of $0 \mathrm{Vavg}$. The voltage is applied by a function generator followed by a high voltage amplifier.

Mesomorphism studies. Mesomorphism was studied by hot stage polarizing microscopy using a Nikon polarized optical microscope equipped with a Linkam THMS600 hot stage, a TMS94 temperature controller, a Nikon -DSFi2 camera.

SEM analysis were realized in the CMEBA -UMS 2001 ScanMat with a JEOL JSM $7100 \mathrm{~F}$

Preparation of the PDLC cells. All Preparations were realized in normal atmosphere. The monomer/LC mixtures were heated at $60^{\circ} \mathrm{C}$ to obtain homogenous samples. Blends were then injected by capillarity into LC cells deposited on a hotplate at $60^{\circ} \mathrm{C}$. The $\mathrm{LC}$ cells were then cured by UV irradiation at $365 \mathrm{~nm}(4 \mathrm{~W})$ for 1 hour. Homogenous opaque red-luminescent (under UV) mixtures were obtained. To induce the liquid-crystal/polymer phase segregation, the cells were heated up to $80^{\circ} \mathrm{C}$ and cooled at $20^{\circ} \mathrm{C} / \mathrm{min}$ to $61^{\circ} \mathrm{C}$. After $5 \mathrm{~min}$ at $61^{\circ} \mathrm{C}$, cells were cooled to room temperature following several cooling rates: from $61^{\circ} \mathrm{C}$ to $56^{\circ} \mathrm{C}$ at $0.1{ }^{\circ} \mathrm{C} / \mathrm{min}$, from $56^{\circ} \mathrm{C}$ to $52.5^{\circ} \mathrm{C}$ at $0.05^{\circ} \mathrm{C} / \mathrm{min}$, from $52.5^{\circ} \mathrm{C}$ to $50^{\circ} \mathrm{C}$ at $0.1^{\circ} \mathrm{C} / \mathrm{min}$, from $50^{\circ} \mathrm{C}$ to $40^{\circ} \mathrm{C}$ at $0.5^{\circ} \mathrm{C} / \mathrm{min}$ and from $40^{\circ} \mathrm{C}$ to $20^{\circ} \mathrm{C}$ at $1{ }^{\circ} \mathrm{C} / \mathrm{min}$. This segregation procedure was performed twice. The phase segregation was then controlled by polarized optical microscopy and UV irradiation as depicted in Figure S1-4.

\section{PDLC Cells composition.}

Control cell: $60 \mathrm{wt} \%$ of a monomer mixture (90 wt.\% MMA, 9 wt.\% Ebecryl® 350 and 1 wt.\% photoinitiator), $40 \mathrm{wt} \%$ of $\mathrm{E} 7 \mathrm{LC}$.

Cell 1: $60 \mathrm{wt} \%$ of a monomer mixture (70 wt.\% MMA, 20 wt. $\%(\mathrm{Cat})_{2} \mathrm{Mo}_{6} \mathrm{I}_{8}\left(\mathrm{OCOC}_{2} \mathrm{~F}_{5}\right)_{6}, 9$ wt.\% Ebecryl® 350 and $1 \mathrm{wt} . \%$ photoinitiator), $40 \mathrm{wt} \%$ of E7 LC. 
Cell 2: $60 \mathrm{wt} \%$ of a monomer mixture (70 wt.\% MMA, 20 wt.\% $(\mathrm{Cat})_{2} \mathrm{Mo}_{6} \mathrm{I}_{8}\left(\mathrm{OCOC}_{2} \mathrm{~F}_{5}\right)_{6}, 9$ wt.\% Ebecryl $\AA^{\circledR} 350$ and 1 wt.\% photoinitiator), $40 \mathrm{wt} \%$ of a LC mixture containing 5 wt.\% of clustomesogen in E7 LC.

Cell 3: 60 wt $\%$ of a monomer mixture (90 wt.\% MMA, 9 wt.\% Ebecryl ${ }^{\circledR} 350$ and 1 wt.\% photoinitiator), $40 \mathrm{wt} \%$ of a LC mixture containing $5 \mathrm{wt} . \%$ of clustomesogen in E7 LC.

\section{ASSOCIATED CONTENT}

\section{Supporting Information.}

The following files are available free of charge.

Polarized optical micrographs, emission spectra, emission decay map and integrated profiles, transmittance spectra, emission response on the edge studies. (PDF)

Video of cell 2 under $365 \mathrm{~nm}$ irradiation when a voltage is applied (mp4)

\section{AUTHOR INFORMATION}

\section{Corresponding Author}

* E-mail: yann.molard@univ-rennes1.fr

\section{Author Contributions}

The manuscript was written through contributions of all authors. All authors have given approval to the final version of the manuscript.

The authors declare no competing financial interest.

\section{Funding Sources}

Agence Nationale de la Recherche 


\section{ACKNOWLEDGMENT}

ANR Renoir is acknowledged for financial support. L. Joanny and F. Gouttefangeas from CMEBA -UMS 2001 ScanMat are acknowledged for SEM measurements.

\section{REFERENCES}

1. Directive 2010/31/EU of the European Parliament and of the Council of 19 May 2010 on the Energy Performance of Buildings (recast). Union, Official J. Eur. Union, 2010; Vol. L153, 1335.

2. Debije, M. G.; Verbunt, P. P. C., Thirty Years of Luminescent Solar Concentrator Research: Solar Energy for the Built Environment. Adv. Energy Mater. 2012, 2 (1), 12-35.

3. van Sark, W. G. J. H. M., Luminescent Solar Concentrators - A Low Cost Photovoltaics Alternative. Renewable Energy 2013, 49, 207-210.

4. Meinardi, F.; Bruni, F.; Brovelli, S., Luminescent Solar Concentrators for BuildingIntegrated Photovoltaics. Nat. Rev. Mater. 2017, 2, 17072.

5. Rafiee, M.; Chandra, S.; Ahmed, H.; McCormack, S. J., An Overview of Various Configurations of Luminescent Solar Concentrators for Photovoltaic Applications. Optical Materials 2019, 91, 212-227.

6. Goetzberger, A.; Greube, W., Solar Energy Conversion with Fluorescent Collectors. Appl. Phys. 1977, 14 (2), 123-139.

7. Tonezzer, M.; Gutierrez, D.; Vincenzi, D., Luminescent Solar Concentrators - State of the Art and Future Perspectives. In Solar Cell Nanotechnology, Tiwari, A.; Boukherroub, R.; Sharon, M., Eds. 2013. 
8. Zhao, Y.; Lunt, R. R., Transparent Luminescent Solar Concentrators for Large-Area Solar Windows Enabled by Massive Stokes-Shift Nanocluster Phosphors. Adv. Energy Mater. 2013, 3 (9), 1143-1148.

9. Meinardi, F.; Colombo, A.; Velizhanin, K. A.; Simonutti, R.; Lorenzon, M.; Beverina, L.; Viswanatha, R.; Klimov, V. I.; Brovelli, S., Large-Area Luminescent Solar Concentrators Based on 'Stokes-Shift-Engineered' Nanocrystals in a Mass-Polymerized PMMA Matrix. Nat. Photonics 2014, 8 (5), 392-399.

10. Meinardi, F.; McDaniel, H.; Carulli, F.; Colombo, A.; Velizhanin, K. A.; Makarov, N. S.; Simonutti, R.; Klimov, V. I.; Brovelli, S., Highly Efficient Large-Area Colourless Luminescent Solar Concentrators Using Heavy-Metal-Free Colloidal Quantum Dots. Nat. Nanotechnol. 2015, $10,878-885$.

11. Meinardi, F.; Ehrenberg, S.; Dhamo, L.; Carulli, F.; Mauri, M.; Bruni, F.; Simonutti, R.; Kortshagen, U.; Brovelli, S., Highly Efficient Luminescent Solar Concentrators Based on EarthAbundant Indirect-Bandgap Silicon Quantum Dots. Nat. Photonics 2017, 11, 177.

12. Yang, C.; Lunt, R. R., Limits of Visibly Transparent Luminescent Solar Concentrators. Adv. Opt. Mater. 2017, 5 (8), 1600851.

13. Baetens, R.; Jelle, B. P.; Gustavsen, A., Properties, Requirements and Possibilities of Smart Windows for Dynamic Daylight and Solar Energy Control in Buildings: A State-of-the-Art Review. Sol. Energy Mater. Sol. Cells 2010, 94 (2), 87-105.

14. Bechinger, C.; Ferrere, S.; Zaban, A.; Sprague, J.; Gregg, B. A., Photoelectrochromic Windows and Displays. Nature 1996, 383 (6601), 608-610. 
15. Lampert, C. M., Smart Switchable Glazing for Solar Energy and Daylight Control. Sol. Energy Mater. Sol. Cells 1998, 52 (3-4), 207-221.

16. Thakur, V. K.; Ding, G.; Ma, J.; Lee, P. S.; Lu, X., Hybrid Materials and Polymer Electrolytes for Electrochromic Device Applications. Adv. Mater. 2012, 24 (30), 4071-4096.

17. Mateen, F.; Oh, H.; Jung, W.; Lee, S. Y.; Kikuchi, H.; Hong, S.-K., Polymer Dispersed Liquid Crystal Device with Integrated Luminescent Solar Concentrator. Liq. Cryst. 2018, 45 (4), 498-506.

18. Mateen, F.; Ali, M.; Oh, H.; Hong, S.-K., Nitrogen-Doped Carbon Quantum Dot Based Luminescent Solar Concentrator Coupled with Polymer Dispersed Liquid Crystal Device for Smart Management of Solar Spectrum. Solar Energy 2019, 178, 48-55.

19. Murray, J.; Ma, D.; Munday, J. N., Electrically Controllable Light Trapping for SelfPowered Switchable Solar Windows. ACS Photonics 2017, 4 (1), 1-7.

20. Chen, R.-T.; Chau, J. L. H.; Hwang, G.-L., Design and Fabrication of Diffusive Solar Cell Window. Renewable Energy 2012, 40 (1), 24-28.

21. Traverse, C. J.; Pandey, R.; Barr, M. C.; Lunt, R. R., Emergence of Highly Transparent Photovoltaics for Distributed Applications. Nat. Energy 2017, 2 (11), 849-860.

22. Cotton, F. A., Metal Atom Clusters in Oxide Systems. Inorg. Chem. 1964, 3 (9), 12171220.

23. Amela-Cortes, M.; Molard, Y.; Paofai, S.; Desert, A.; Duvail, J.-L.; Naumov, N. G.; Cordier, S., Versatility of the Ionic Assembling Method to Design Highly Luminescent PMMA 
Nanocomposites Containing $\left[\mathrm{M}_{6} \mathrm{Q}_{8}^{\mathrm{i}} \mathrm{L}_{6}^{\mathrm{a}}\right]^{\mathrm{n}-}$ Octahedral Nano-Building Blocks. Dalton Trans. 2016, $45(1), 237-245$.

24. Kirakci, K.; Kubat, P.; Dusek, M.; Fejfarova, K.; Sicha, V.; Mosinger, J.; Lang, K., A Highly Luminescent Hexanuclear Molybdenum Cluster - A Promising Candidate Toward Photoactive Materials. Eur. J. Inorg. Chem. 2012, (19), 3107-3111.

25. Zhou, Y.; Zhao, H.; Ma, D.; Rosei, F., Harnessing the Properties of Colloidal Quantum Dots in Luminescent Solar Concentrators. Chem. Soc. Rev. 2018, 47 (15), 5866-5890.

26. Cordier, S.; Grasset, F.; Molard, Y.; Amela-Cortes, M.; Boukherroub, R.; Ravaine, S.; Mortier, M.; Ohashi, N.; Saito, N.; Haneda, H., Inorganic Molybdenum Octahedral Nanosized Cluster Units, Versatile Functional Building Block for Nanoarchitectonics. J. Inorg. Organomet. Polym. Mater. 2015, 25 (2), 189-204.

27. Doane, J. W.; Vaz, N. A.; Wu, B. G.; Žumer, S., Field Controlled Light Scattering from Nematic Microdroplets. Appl. Phys. Lett. 1986, 48 (4), 269-271.

28. Molard, Y.; Ledneva, A.; Amela-Cortes, M.; Circu, V.; Naumov, N. G.; Meriadec, C.; Artzner, F.; Cordier, S., Ionically Self-Assembled Clustomesogen with Switchable Magnetic/Luminescence Properties Containing $\left[\mathrm{Re}_{6} \mathrm{Se}_{8}(\mathrm{CN})_{6}\right]^{\mathrm{n}-}(\mathrm{n}=3,4)$ Anionic Clusters. Chem. Mater. 2011, 23 (23), 5122-5130.

29. Amela-Cortes, M.; Garreau, A.; Cordier, S.; Faulques, E.; Duvail, J.-L.; Molard, Y., Deep Red Luminescent Hybrid Copolymer Materials with High Transition Metal Cluster Content. J. Mater. Chem. C 2014, 2 (8), 1545-1552. 
30. Amela-Cortes, M.; Paofai, S.; Cordier, S.; Folliot, H.; Molard, Y., Tuned Red NIR Phosphorescence of Polyurethane Hybrid Composites Embedding Metallic Nanoclusters for Oxygen Sensing. Chem. Commun. 2015, 51, 8177-8180.

31. Prevot, M.; Amela-Cortes, M.; Manna, S. k.; Cordier, S.; Roisnel, T.; Folliot, H.; Dupont, L.; Molard, Y., Electroswitchable Red-NIR Luminescence of Ionic Clustomesogen Containing Nematic Liquid Crystalline Device. J. Mater. Chem. C 2015, 3 (20), 5152-5161.

32. Prevot, M.; Amela-Cortes, M.; Manna, S. K.; Lefort, R.; Cordier, S.; Folliot, H.; Dupont, L.; Molard, Y., Design and Integration in Electro-Optic Devices of Highly Efficient and Robust Red-NIR Phosphorescent Nematic Hybrid Liquid Crystals Containing $\left[\mathrm{Mo}_{6} \mathrm{I}_{8}\left(\mathrm{OCOC}_{\mathrm{n}} \mathrm{F}_{2 \mathrm{n}+1}\right)_{6}\right]^{2-}(\mathrm{n}$ = 1, 2, 3) Nanoclusters. Adv. Funct. Mater. 2015, 25 (31), 4966-4975.

33. Wood, S. M.; Prévôt, M.; Amela-Cortes, M.; Cordier, S.; Elston, S. J.; Molard, Y.; Morris, S. M., Polarized Phosphorescence of Isotropic and Metal-Based Clustomesogens Dispersed into Chiral Nematic Liquid Crystalline Films. Adv. Optical Mater. 2015, 3 (10), 1368-1372.

34. Molard, Y.; Dorson, F.; Circu, V.; Roisnel, T.; Artzner, F.; Cordier, S., Clustomesogens: Liquid Crystal Materials Containing Transition Metal Clusters. Angew. Chem. Int. Ed. Engl. 2010, 49 (19), 3351-3355.

35. Molard, Y., Clustomesogens: Liquid Crystalline Hybrid Nanomaterials Containing Functional Metal Nanoclusters. Acc. Chem. Res. 2016, 49 (8), 1514-1523.

36. Drzaic, P. S., Liquid Crystal Dispersions. World Scientific: 1995; Vol. 1, p 448. 
37. Deshmukh, R. R., Electro-optic and Dielectric Responses in PDLC Composite Systems. In Liquid Crystalline Polymers, Processing and Applications, Thakur, V. K.; Kessler, M. R., Eds. Springer, Cham: 2015; Vol. 2, pp 169-195.

38. Jackson, J. A.; Turro, C.; Newsham, M. D.; Nocera, D. G., Oxygen Quenching of Electronically Excited Hexanuclear Molybdenum and Tungsten Halide Clusters. J. Phys. Chem. 1990, 94 (11), 4500-4507.

39. Robin, M.; Dumait, N.; Amela-Cortes, M.; Roiland, C.; Harnois, M.; Jacques, E.; Folliot, H.; Molard, Y., Direct Integration of Red-NIR Emissive Ceramic-like AnM6Xi8Xa6 Metal Cluster Salts in Organic Copolymers Using Supramolecular Interactions. Chem. Eur. J. 2018, 24 (19), $4825-4829$.

40. Yang, D.-K.; Wu, S.-T., Fundamentals of liquid crystal devices. John Wiley \& Sons, Ltd: 2006; p 394.

41. Montgomery, G. P.; West, J. L.; Tamura-Lis, W., Light Scattering from Polymer-Dispersed Liquid Crystal Films: Droplet Size Effects. J. Appl. Phys. 1991, 69 (3), 1605-1612.

42. Born, M.; Wolf, E., Principles of Optics: Electromagnetic Theory of Propagation, Interference and Diffraction of Light. 7 ed.; Cambridge University Press: Cambridge, 1999.

43. Perlmutter, S. H.; Doroski, D.; Moddel, G., Degradation of Liquid Crystal Device Performance Due to Selective Adsorption of Ions. Appl. Phys. Lett. 1996, 69 (9), 1182-1184.

44. Ferrari, J. A.; Dalchiele, E. A.; Frins, E. M.; Gentilini, J. A.; Perciante, C. D.; Scherschener, E., Effect of Size Polydispersity in Polymer-Dispersed Liquid-Crystal Films. J. Appl. Phys. 2008, 103 (8), 084505. 
45. Ohta, S.; Inasawa, S.; Yamaguchi, Y., Size Control of Phase-Separated Liquid Crystal Droplets in a Polymer Matrix Based on The Phase Diagram. J. Polym. Sci., Part B: Polym. Phys. 2012, 50 (12), 863-869.

46. Kelly, J. R.; Wu, W., Multiple Scattering Effects in Polymer Dispersed Liquid Crystals. Liq. Cryst. 1993, 14 (6), 1683-94.

47. Drzaic, P. S., Droplet Density, Droplet Size, and Wavelength Effects in PDLC Light Scattering. Mol. Cryst. Liq. Cryst. Sci. Technol., Sect. A 1995, 261 (1), 383-392.

48. Song, P.; Gao, Y.; Wang, F.; Zhang, L.; Xie, H.; Yang, Z.; Yang, H., Studies on the ElectroOptical and The Light-Scattering Properties of PDLC Films with The Size Gradient of The LC Droplets. Liq. Cryst. 2015, 42 (3), 390-396. 
Table of content graphic.

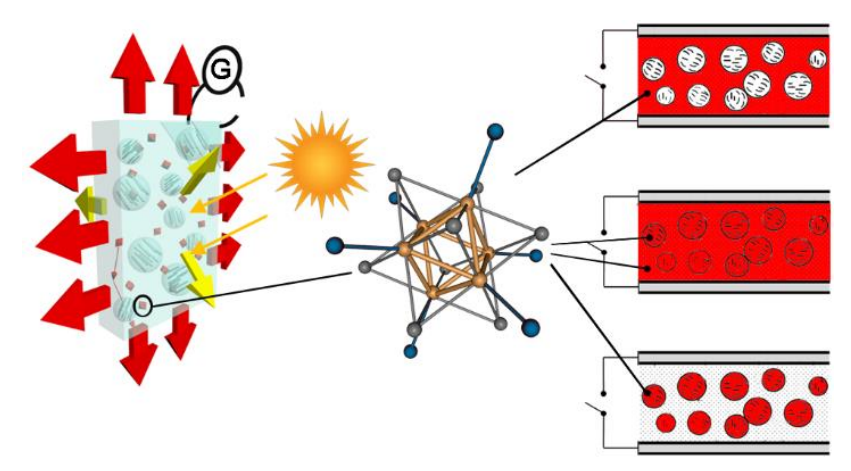

